American Journal of Pharmaceutical Education 2019; 83 (9) Article 7274.

\title{
RESEARCH
}

\section{Pharmacy Student Perceptions of the Entrustable Professional Activities}

\author{
Amy L. Pittenger, PharmD, PhD, ${ }^{a}$ Brenda L. Gleason, PharmD, ${ }^{b}$ Stuart T. Haines, PharmD, ${ }^{c}$ \\ Stephen Neely, MPH, ${ }^{\mathrm{d}}$ Melissa S. Medina, EdD ${ }^{\mathrm{d}}$ \\ ${ }^{a}$ University of Minnesota, College of Pharmacy, Minneapolis, Minnesota \\ ${ }^{\mathrm{b}}$ St. Louis College of Pharmacy, St. Louis, Missouri \\ ${ }^{\mathrm{c}}$ University of Mississippi School of Pharmacy, Jackson, Mississippi \\ ${ }^{\mathrm{d}}$ University of Oklahoma College of Pharmacy, Oklahoma City, Oklahoma \\ Submitted by July 16, 2018; accepted March 6, 2019; published November 2019.
}

\begin{abstract}
Objective. To determine pharmacy students' perceptions and self-reported preparedness to perform the 15 core entrustable professional activities (EPA) established by the American Association of Colleges of Pharmacy for new pharmacy graduates.

Methods. A random sample of Doctor of Pharmacy (PharmD) students from all four professional years at four universities were asked to indicate whether each of the 15 EPA statements was relevant to the practice of pharmacy and whether pharmacists were expected to perform the activity in multiple practice settings. Participants rated their self-perceived level of entrustability for each activity and indicated which three EPAs they felt most and least prepared to perform.

Results. Four hundred twenty-three usable responses were received. The majority ( $\geq 85 \%)$ of students rated all of the EPA statements as relevant and $\geq 67 \%$ indicated that pharmacists were expected to perform them in multiple practice settings with a high percentage of agreement. Students' perceived need for supervision decreased from the P1 to P4 years. These data suggest that students' confidence to perform some activities grew as they gained experience and knowledge. However, in some cases, the self-perceived need for supervision regressed as students better understood the complexity of the activity. The EPA statements students felt most and least prepared to perform varied by year in the program.

Conclusion. The core EPA statements were consistently rated by pharmacy students as relevant to pharmacy practice and as an expectation in multiple settings. Students perceived that they require less supervision when performing EPA activities as they progressed through the curriculum.
\end{abstract}

Keywords: entrustable professional activities, pharmacy students, outcomes

\section{INTRODUCTION}

Entrustable professional activities (EPAs) are duties that a healthcare provider is expected to competently perform. ${ }^{1}$ Collectively, the EPAs for a profession describe the essential work of the discipline or occupation. Entrustable professional activities are intended to guide the education and training of health professionals and offer a practical approach to assessing competence in real-world settings. ${ }^{2}$ Entrustable professional activities have been described for medical school graduates and for internal medicine, pediatric medicine, family medicine, and pathology residencies. ${ }^{3,4}$ In 2016, the American Association of Colleges of Pharmacy (AACP) published a list of 15 EPA statements for new pharmacy graduates which define a set of tasks and

Corresponding Author: Amy L. Pittenger, University of Minnesota, College of Pharmacy, 308 Harvard St. SE; WDH 5110; 1332A, Minneapolis, MN 55455. Tel: 612-625-7629.

Email: alp@umn.edu. functions that all pharmacists should be able to perform. ${ }^{5}$ While many stakeholders provided input into the development of the EPAs published by AACP and experienced practitioner-educators have expressed their support of the 15 core EPAs, it is unknown whether pharmacy students consider the EPAs relevant to their future work or believe they are being sufficiently prepared to perform them. ${ }^{4,5}$

Entrustable professional activities are now being used by colleges and schools as a tool to guide curricular development and assess each student's progress towards independence. ${ }^{6-8}$ Ultimately, the Doctor of Pharmacy (PharmD) curriculum should prepare graduates to perform the EPAs autonomously, requiring only indirect supervision at the time of licensure. ${ }^{5}$ Given that EPAs are a relatively new construct, soliciting input from pharmacy students on their perceptions can provide useful information regarding the clarity of the statements and may reveal gaps in their understanding about the roles and responsibilities of pharmacists. 


\section{American Journal of Pharmaceutical Education 2019; 83 (9) Article 7274.}

This study involved capturing pharmacy students' reactions to the 15 core EPA statements using a survey and then analyzing their responses. ${ }^{1}$ Specifically, we attempted to answer the following questions: Do pharmacy students believe the EPAs are relevant to the practice of pharmacy? Are they an expectation in most practice settings? Do pharmacy students feel prepared to autonomously perform the EPAs as they progress toward graduation?

\section{METHODS}

A random sample of PharmD students from each of the four professional years at four institutions (Universities of Minnesota, Mississippi, Oklahoma, and St. Louis College of Pharmacy) were invited to participate in this study. A power analysis was conducted using G*Power, version 3.1.9.2 (http://www.gpower.hhu.de/) to determine an appropriate sample size given a proportional difference of $20 \%$ (ie, $90 \%$ vs $70 \%$ agreement), power of 0.80 , and a Bonferroni-adjusted alpha of 0.00833 . We set the alpha lower because we anticipated conducting multiple pairwise comparisons between program years. Based on these parameters, a total sample size of 400 would be needed. Using a multistage sample approach, we randomly selected students, stratified by professional year and school. ${ }^{9,10}$ This was done to reduce overrepresentation of respondents from larger schools or from a particular class year. For example, students for the P3 or P4 year might be more inclined to respond to the survey instrument, causing their responses to be more heavily weighted in the overall analysis. By ensuring a relatively equal number of respondents in each stratum, we attempted to create a representative sample from each professional year and school. Therefore, the study was designed to include responses from 25 students from each professional year cohort at each school for a projected institution total of 100 students and an overall study total of 400 students. The study received approval (exempt status) from the institutional review boards at the four participating institutions.

A four-part survey instrument that included 56 questions was administered to student participants via the online survey tool, Qualtrics (https://www.qualtrics.com/ Provo, UT, and Seattle, WA). Part 1 of the survey instrument contained demographic questions regarding the participant's age group, institution attended, year in the program, level of awareness of EPAs, and estimated hours of experience in pharmacy practice accumulated to date, including pharmacy technician and intern hours. Part 2 of the survey instrument asked student participants to indicate if the EPA statements were relevant to the practice of pharmacy and expected of pharmacists in multiple prac- tice settings. This part of the survey instrument was adapted from the validated Quality of Entrustable Professional Activities (QUEPA) tool initially developed for internal medicine residents. ${ }^{13}$ The QUEPA survey questions were modified to reflect differences in pharmacy practice versus medical practice, account for the pharmacy specific EPA statements published by AACP, and to coincide with EPA survey questions previously administered to experienced practitioner-educators. ${ }^{4}$ An additional modification to the QUEPA tool was the change from scaled responses to a binary response of yes or no. Our version of the instrument was not validated after these modifications. Part 3 of the survey asked participants to read a patient case scenario to provide context and then to rate their current level of autonomy (level of entrustability) for each EPA. Eight community practice pharmacists (two from each study institution's region) vetted the scenario to ensure that it was a complex and realistic case that a new pharmacy graduate would likely encounter. Last, in part 4 of the survey instrument, respondents were asked to select the three EPA statements they believed they were most prepared to perform and the three they believed they were least prepared to perform at this point in their education.

A draft survey instrument was piloted with 11 juniorlevel pre-pharmacy students (ie, undergraduate students accepted into the pharmacy program but not yet pharmacy students) enrolled at St. Louis College of Pharmacy. The purpose of the pilot test was to determine the time required for survey administration, the technical functionality of the survey instrument, and the clarity of the instructions and questions. The final survey instrument, instructions, and items can be viewed here (https:// www.pharmacy.umn.edu/sites/pharmacy.umn.edu/files/ appendix_survey.docx).

A randomized number list for each of the four program years was used to randomly select students to participate in the study at each institution. For the first round of data collection, 30 students from each professional year at each institution were invited to participate via an email that explained the purpose of the study, briefly defined EPAs, and provided a link to the survey instrument. Participants were invited in February 2018 (day 1) and reminded on day 8 and day 15 . On day 15 , study invitations were sent to additional students if the 25-participant goal for each professional year had not been met. The number of additional students invited equaled the shortfall for the professional year at each institution. For example, the goal of 25 minus the $20 \mathrm{P} 1$ respondents equaled a shortfall of five P1 respondents (shortfall group 1), resulting in a total of 35 invitations sent to P1 students on day 15 (five new invitations and 30 reminders). On day 


\section{American Journal of Pharmaceutical Education 2019; 83 (9) Article 7274.}

22, shortfall group 1 received an email reminder and a new shortfall group 2 was invited to participate. The initial 30 students who had been invited did not receive any further reminder emails. This pattern continued every seven days, ie, invited participants would receive reminder emails for only two weeks and then a new shortfall group would be added to replace the dropped shortfall group. All data collection was completed by April 2018.

Results were aggregated into descriptive summaries and compared based on demographic characteristics. Categorical variables were reported in percentages and evaluated using Pearson chi-square tests. Exact Pearson chi-square tests were used if expected cell counts were less than five. In part 2 of the survey instrument, participants were asked to evaluate EPA statements on two separate attributes (relevancy and expectation in multiple practice settings). Participants were said to have agreed with an item if they had responded yes to a yes/no question. Agreement does not refer to paired inter-rater agreement or reliability. To determine if differences in agreement exist among program years (P1-P4), a chi square test was performed on the $2 \times 4$ contingency table. The total number of statements a participant agreed with was reported with median (interquartile range, IQR), and differences in program years were evaluated using Kruskal-Wallis tests. Statistical significance was set at $p<.05$. All analyses were conducted using SAS software, version 9.4 (SAS Institute, Cary, NC).

\section{RESULTS}

The survey instrument was distributed to 1161 pharmacy students at the four participating institutions. Four hundred eighty-eight responses were received between February 20 and April 27, 2018 Sixty-five responses were excluded because the participant only completed part one of the survey instrument. The demographic information for the participants across the four institutions is detailed in Table 1. Statistical differences between age groups and pharmacy work experience reflect the variability in the structure of the four participating PharmD programs. Because of the recruitment design, there were similar numbers of students for each program year for each of the four participating institutions. As anticipated, the University of Minnesota had higher numbers of students familiar with EPA statements, as this was the only institution of the four that was using EPA statements at the time of the study (although not the AACP's EPA statements) as their evaluation strategy for advanced pharmacy practice experience.

Of the 423 usable responses, 48 (11.3\%) students stopped after completing part 2 (EPA relevancy/setting questions), two (0.4\%) students stopped after completing part 3 (self-reported skill level), and 373 (88.2\%) students completed the entire survey. The overall response rate was
$36 \%$ of the 1161 invitations sent. Because of our distribution methods, each institution invited different numbers of students to participate in the survey. Response rates differed by institution: St. Louis College of Pharmacy, 25\% of 436 invitations sent; University of Minnesota, $32 \%$ of 317 ; University of Mississippi, 46\% of 216; and University of Oklahoma, $59 \%$ of $192, p=.001$. However, the goal set after conducting a power analysis of obtaining 25 completed survey instruments per professional year at each of the four study institutions was met and, in some instances, exceeded.

Table 2 details the overall level of agreement for both relevancy and expectation in multiple practice setting attributes. Overall, there was high agreement that the EPAs were relevant to pharmacy practice. The percent agreement was $>94 \%$ for 14 out of 15 EPA statements. The lowest level of agreement was $85 \%$ of students indicating that "Create a written plan for continuous professional development" was a relevant professional activity for pharmacists. The level of agreement across student program years were significantly different for two EPA statements: "Analyze information to determine the effects of medication therapy, identify medication-related problems, and prioritize health-related needs," and "Minimize adverse drug events and medication errors." The level of agreement for these two statements increased significantly among students from the P1 year to the P2. The median (IQR) number of statements with which students agreed was 15 (ie, 15 of 15) and did not differ by program year.

The overall level of agreement that the EPA statements represent activities that pharmacists are expected to perform in multiple practice settings varied, but there was $90 \%$ agreement or higher for nine of the 15 statements. The lowest overall percent agreement was $67 \%$ for the statement, "Create a written plan for continuous professional development." No significant differences in the percent of agreement across program years were found for 13 of the statements. Significant differences were observed in two statements. Students in the P2, P3, and P4 years universally (100\%) agreed that "Minimize adverse drug reactions and medication errors," was an expected professional activity in multiple practice settings compared to $96 \%$ of P1 students. The P1 and P2 students were less likely than P3 and P4 students to agree that the EPA "Maximize the appropriate use of medications in a population" was an expected professional activity of pharmacists in multiple practice settings. The median number of statements that students agreed were expected in multiple practice settings was $14(\mathrm{IQR}=12-15)$ and was similar across program year.

Self-reported ability to perform each EPA statement without supervision increased across program year (Table 3 ). The median response among P1 students was 2 , need direct supervision, on 13 of the 15 statements. The median 


\section{American Journal of Pharmaceutical Education 2019; 83 (9) Article 7274.}

Table 1. Demographics of Pharmacy Students at Four Universities That Participated in a Study to Determine Their Perceptions of Entrustable Professional Activities

\begin{tabular}{|c|c|c|c|c|c|c|}
\hline Variable & $\begin{array}{c}\text { St. Louis } \\
\text { College of } \\
\text { Pharmacy } \\
(n=109)\end{array}$ & $\begin{array}{c}\text { University } \\
\text { of } \\
\text { Minnesota } \\
\text { College } \\
\text { of Pharmacy } \\
(n=101)\end{array}$ & $\begin{array}{c}\text { University } \\
\text { of } \\
\text { Mississippi } \\
\text { School } \\
\text { of Pharmacy } \\
(n=100)\end{array}$ & $\begin{array}{c}\text { University } \\
\text { of } \\
\text { Oklahoma } \\
\text { College } \\
\text { of Pharmacy } \\
(n=113)\end{array}$ & $\begin{array}{c}\text { Total } \\
(n=423)\end{array}$ & $\begin{array}{c}\text { Chi- } \\
\text { Square } \\
p \text { Value }\end{array}$ \\
\hline \multicolumn{7}{|l|}{$\overline{\text { Age }}$} \\
\hline $20-23$ years old & $63(58)$ & $17(17)$ & $52(52)$ & $29(26)$ & $161(38)$ & $<.0001$ \\
\hline 24-27 years old & $34(31)$ & $64(63)$ & $45(45)$ & $54(48)$ & $197(47)$ & \\
\hline 28-32 years old & $5(5)$ & $11(11)$ & $3(3)$ & $18(16)$ & $37(9)$ & \\
\hline 33 years old or older & $7(6)$ & $9(9)$ & $0(0)$ & $12(11)$ & $28(7)$ & \\
\hline \multicolumn{7}{|l|}{ Year in program } \\
\hline First year $(\mathrm{P} 1)$ & $25(23)$ & $25(25)$ & $26(26)$ & $29(26)$ & $105(25)$ & .99 \\
\hline Second year (P2) & $29(27)$ & $25(25)$ & $20(20)$ & $28(25)$ & $102(24)$ & \\
\hline Third year $(\mathrm{P} 3)$ & $25(23)$ & $23(23)$ & $28(28)$ & $26(23)$ & $102(24)$ & \\
\hline Fourth year $(\mathrm{P} 4)$ & $30(28)$ & $28(28)$ & $26(26)$ & $30(27)$ & $114(27)$ & \\
\hline \multicolumn{7}{|l|}{ Level of awareness/understanding of Entrustable } \\
\hline This is the first time I have heard of EPAs & $78(72)$ & $34(34)$ & $77(77)$ & $82(73)$ & $271(64)$ & $<.0001$ \\
\hline $\begin{array}{l}\text { I have heard of EPAs but I don't really know } \\
\text { what they are or how they are used }\end{array}$ & $27(25)$ & $40(40)$ & $21(21)$ & $29(26)$ & $117(28)$ & \\
\hline $\begin{array}{l}\text { I'm aware of EPAs and understand how they are } \\
\text { or will be used }\end{array}$ & $4(4)$ & $27(27)$ & $2(2)$ & $2(2)$ & $35(8)$ & \\
\hline \multicolumn{7}{|l|}{ Accumulated pharmacy practice experience to date } \\
\hline Less than 500 hours & $17(16)$ & $17(17)$ & $28(28)$ & $39(35)$ & $101(24)$ & .005 \\
\hline 500 to 1,500 hours & $29(27)$ & $27(27)$ & $32(32)$ & $27(24)$ & $115(27)$ & \\
\hline More than 1,500 hours & $63(58)$ & $57(56)$ & $40(40)$ & $47(42)$ & 207 (49) & \\
\hline
\end{tabular}

response among P2 students was 3, need indirect supervision, for 10 of the 15 statements. The median response among P3 students was 3, need indirect supervision, on about half of the EPA statements, and 4, need periodic supervision, on the other half. Finally, the median response among P4 students was 4, need periodic supervision, on 13 of the statements. Within Table 3, the transition in the median self-perceived supervisory needs for P1 students to P4 students decreases as the level of self-perceived entrustability increases (higher level of entrustability), indicating greater confidence in performing each EPA statement.

Students were asked to select the three EPA statements they felt most prepared to fulfill at this point in their education (Table 4). Regardless of program year, the majority of students included the EPA statement "Collect information to identify a patient's medication-related problems and health-related needs" among the three activities they felt most prepared to perform. Sixty-four percent of P1 students selected this EPA statement, with decreasing percentages across the other program years: $\mathrm{P} 2,62 \%$; P3, 52\%; and P4, 51\%).

The second most often selected EPA statement was "Fulfill a medication order." However, this EPA state- ment was most frequently selected by P1 students, with $68 \%$ saying they were most prepared to perform this activity. The frequency with which this statement was selected diminished across program years $(\mathrm{P} 1=68 \%$, $\mathrm{P} 2=54 \%, \mathrm{P} 3=46 \%$, and $\mathrm{P} 4=45 \%$ ). The third mostly frequently selected EPA statement differed by year in program. The EPA statements students indicated they were most prepared to perform were significantly different across program years. Overall, significant differences in students' responses across years in the curriculum were found on eight of the 15 EPA statements.

Of the EPAs that students indicated they were least prepared to perform, a high percentage of students selected "Overseeing the pharmacy operations for an assigned work shift." The percentage who indicated they were least prepared to perform this EPA steadily increased each year (from $31 \%$ for P1s to $57 \%$ for P4s). In addition, the percentage of students who indicated they were least prepared to "Create a written plan for continuous professional development" steadily increased from the P1 to the P4 year (24\% for P1 students to $53 \%$ for P4 students). Conversely, while "Establish patient-centered goals and create a care plan," was among the EPAs 


\section{American Journal of Pharmaceutical Education 2019; 83 (9) Article 7274.}

Table 2. Pharmacy Students' Agreement With EPA Statement Attribute for Both Relevancy and Expectation Within Multiple Practice Settings

\begin{tabular}{|c|c|c|c|c|c|c|}
\hline \multirow[b]{2}{*}{ EPA Statement } & $\begin{array}{l}\text { EPA is } \\
\text { Relevant }\end{array}$ & \multicolumn{5}{|c|}{ EPA is Expected in Multiple Practice Settings } \\
\hline & $\begin{array}{c}\text { Total } \\
\mathrm{n}=423 \\
(\%)\end{array}$ & $\begin{array}{c}\text { Total } \\
\mathrm{n}=423 \\
(\%)\end{array}$ & $\begin{array}{c}\mathrm{P1} \\
\mathrm{n}=105 \\
(\%)\end{array}$ & $\begin{array}{c}\mathrm{P2} \\
\mathrm{n}=102 \\
(\%)\end{array}$ & $\begin{array}{c}\text { P3 } \\
\mathrm{n}=102 \\
(\%)\end{array}$ & $\begin{array}{c}\mathrm{P4} \\
\mathrm{n}=114 \\
(\%)\end{array}$ \\
\hline \multicolumn{7}{|l|}{ Patient Provider Role } \\
\hline $\begin{array}{l}\text { Collect information to identify a patient's } \\
\text { medication-related problems and health-related needs. }\end{array}$ & 99 & 94 & 96 & 93 & 93 & 94 \\
\hline $\begin{array}{l}\text { Analyze information to determine the effects of } \\
\text { medication therapy, identify medication-related } \\
\text { problems, and prioritize health-related needs. }\end{array}$ & $99^{\mathrm{b}}$ & 92 & 90 & 94 & 91 & 91 \\
\hline $\begin{array}{l}\text { Establish patient-centered goals and create a care plan for } \\
\text { a patient in collaboration with the patient, caregiver(s), } \\
\text { and other health professionals that is evidence-based } \\
\text { and cost-effective. }\end{array}$ & 99 & 80 & 87 & 78 & 78 & 78 \\
\hline $\begin{array}{l}\text { Implement a care plan in collaboration with the patient, } \\
\text { caregivers, and other health professionals. }\end{array}$ & 99 & 79 & 85 & 79 & 79 & 73 \\
\hline $\begin{array}{l}\text { Follow-up and monitor a care plan. } \\
\text { Interprofessional Team Member Role }\end{array}$ & 97 & 76 & 73 & 79 & 78 & 73 \\
\hline Collaborate as a member of an interprofessional team. & 100 & 91 & 94 & 91 & 90 & 88 \\
\hline \multicolumn{7}{|l|}{ Population Health Promoter Role } \\
\hline $\begin{array}{l}\text { Identify patients at risk for prevalent diseases in } \\
\text { a population. }\end{array}$ & 94 & 72 & 73 & 69 & 72 & 75 \\
\hline Minimize adverse drug events and medication errors. & $99^{\mathrm{b}}$ & $99^{\mathrm{b}}$ & 96 & 100 & 100 & 100 \\
\hline $\begin{array}{l}\text { Maximize the appropriate use of medications in } \\
\text { a population. }\end{array}$ & 98 & $90^{b}$ & 88 & 81 & 94 & 96 \\
\hline $\begin{array}{l}\text { Ensure that patients have been immunized } \\
\text { against vaccine-preventable diseases. } \\
\text { Information Master Role }\end{array}$ & 98 & 88 & 84 & 85 & 90 & 91 \\
\hline $\begin{array}{l}\text { Educate patients and professional colleagues } \\
\text { regarding the appropriate use of medications. }\end{array}$ & 100 & 97 & 98 & 98 & 96 & 97 \\
\hline $\begin{array}{l}\text { Use evidence-based information to advance patient care. } \\
\text { Practice Manager Role }\end{array}$ & 99 & 91 & 91 & 92 & 88 & 93 \\
\hline $\begin{array}{l}\text { Oversee the pharmacy operations for an assigned } \\
\text { work shift. }\end{array}$ & 97 & 92 & 90 & 88 & 94 & 94 \\
\hline $\begin{array}{l}\text { Fulfill a medication order. } \\
\text { Self-Developer Role }\end{array}$ & 99 & 96 & 94 & 97 & 99 & 95 \\
\hline $\begin{array}{l}\text { Create a written plan for continuous professional } \\
\text { development. }\end{array}$ & 85 & 67 & 68 & 72 & 65 & 64 \\
\hline
\end{tabular}

Abbreviations: P1 = first profession year; P2=second profession year; P3=third profession year; P4=fourth profession year

${ }^{a}$ Breakdown by program year not reported in table because of overall high level of agreement. Agreement was defined as a participant responding

"yes" that the EPA statement exhibited the attribute

${ }^{\mathrm{b}}$ Indicates significant $p$ value for asymptotic or Pearson exact chi-square test

students felt least prepared to perform, the percentage of students indicating this steadily declined from the P1 $(45 \%)$ to the $\mathrm{P} 4(24 \%)$ year.

\section{DISCUSSION}

This study provides evidence that among pharmacy students at four colleges of pharmacy, the AACP Core EPAs for New Pharmacy Graduates are perceived as rele- vant and applicable to multiple work settings. Overall, this study found consistently high agreement ( $\geq 85 \%$ for all 15 statements) among pharmacy students that the EPAs describe activities relevant to entry-level pharmacy practice. Pharmacy students' agreement regarding the relevancy of the EPA statements was consistent across PharmD program years (P1-P4) and between the four institutions. The overall level of agreement was high $(\geq 67 \%$ for all 15 EPA 
American Journal of Pharmaceutical Education 2019; 83 (9) Article 7274.

Table 3. Pharmacy Students' Self-Reported Level of Ability to Perform EPA Statements by Program Year

\begin{tabular}{|c|c|c|c|c|}
\hline \multirow[b]{2}{*}{ EPA Statement } & \multicolumn{4}{|c|}{$\begin{array}{l}\text { Rated Level of Ability to } \\
\text { Perform the EPA Statement, } \\
\text { Median (IQR) }\end{array}$} \\
\hline & P1 n=94 & $\mathrm{P2} n=86$ & P3 n=92 & P4 n=103 \\
\hline $\begin{array}{l}\text { Collect information to identify a patient's medication-related problems and } \\
\text { health-related needs. }\end{array}$ & $2(2-3)$ & $3(3-4)$ & $4(3-5)$ & $4(4-5)$ \\
\hline $\begin{array}{l}\text { Analyze information to determine the effects of medication therapy, identify } \\
\text { medication-related problems, and prioritize health-related needs. }\end{array}$ & $2(1-2)$ & $3(2-3)$ & $3(3-4)$ & $4(3-5)$ \\
\hline $\begin{array}{l}\text { Establish patient-centered goals and create a care plan for a patient in collaboration } \\
\text { with the patient, caregiver(s), and other health professionals that is evidence-based } \\
\text { and cost-effective. }\end{array}$ & $2(1-3)$ & $2(2-3)$ & $3(2-4)$ & $4(3-5)$ \\
\hline $\begin{array}{l}\text { Implement a care plan in collaboration with the patient, caregivers, and other health } \\
\text { professionals. }\end{array}$ & $2(1-2)$ & $2(2-3)$ & $3(2-4)$ & $4(3-5)$ \\
\hline Follow-up and monitor a care plan. & $2(1-3)$ & $3(2-4)$ & $4(3-4)$ & $4(3-5)$ \\
\hline Collaborate as a member of an interprofessional team. & $2(1-4)$ & $3(2-5)$ & $4(3-5)$ & $5(4-5)$ \\
\hline Identify patients at risk for prevalent diseases in a population. & $2(1-3)$ & $3(2-4)$ & $4(3-4)$ & $4(3-5)$ \\
\hline Minimize adverse drug events and medication errors. & $2(1-2)$ & $3(2-3)$ & $3(2-4)$ & $4(4-5)$ \\
\hline Maximize the appropriate use of medications in a population. & $2(1-2)$ & $3(2-3)$ & $3(3-4)$ & $4(3-5)$ \\
\hline Ensure that patients have been immunized against vaccine-preventable diseases. & $3(2-4)$ & $4(3-5)$ & $4(4-5)$ & $5(4-5)$ \\
\hline $\begin{array}{l}\text { Educate patients and professional colleagues regarding the appropriate use of } \\
\text { medications. }\end{array}$ & $2(1-2)$ & $3(2-4)$ & $4(3-5)$ & $4(4-5)$ \\
\hline Use evidence-based information to advance patient care. & $2(1-3)$ & $3(2-4)$ & $4(3-4)$ & $4(3-5)$ \\
\hline Oversee the pharmacy operations for an assigned work shift. & $2(1-3)$ & $2(1-3)$ & $3(2-4)$ & $4(3-5)$ \\
\hline Fulfill a medication order. & $4(2-5)$ & $4(3-5)$ & $5(3-5)$ & $5(4-5)$ \\
\hline Create a written plan for continuous professional development. & $2(1-3)$ & $3(2-4)$ & $3(2-4)$ & $4(3-5)$ \\
\hline
\end{tabular}

Abbreviations: P1 = first professional year; P2 = second professional year; P3=third professional year; P4=fourth professional year

EPA Level of Entrustability: 1=observation only, 2=direct supervision, $3=$ indirect supervision, $4=$ periodic supervision, $5=$ general direction

statements), but greater variability existed among pharmacy students' responses regarding whether the EPA statements were expected activities for pharmacists in multiple practice settings. Interestingly, student agreement that the EPA statement of "Collaborate as a member of an interprofessional team" was expected across multiple practice settings declined as students progressed through the PharmD program years. Although this decline was not significant, it suggests that students may not be observing pharmacist preceptors routinely participate in interprofessional activities in all practice settings. However, this contradicts ratings among experienced practitioner-educators who ranked the interprofessional collaborator role as second highest in both importance and amount of time spent performing. ${ }^{4}$ The potential disconnect between experienced practitioner-educators with close ties to a college and the broader pharmacy practice community regarding interprofessional collaboration should be explored to ensure curricular emphasis and expectations are in alignment with IPPEs and APPEs.

The EPA statement "Create a written plan for continuous professional development" garnered the lowest percentage agreement as being both relevant and an expectation found across multiple settings. As pharmacy practice con- tinues to evolve and change, colleges and schools need to help students gain understanding of the importance of continuing professional development (CPD) and intentionally integrate self-directed learning activities into PharmD curricula, as well as make explicit through preceptor-student discussion prompts how clinicians use CPD in their own careers. The results of this study regarding the importance and challenges related to preparing students for CPD align with input from other pharmacy stakeholders. ${ }^{4,5}$

Student pharmacists self-rated their ability to perform the EPAs in an increasingly independent manner as they progressed through a PharmD program, moving from needing direct supervision in the $\mathrm{P} 1$ year to periodic supervision in the $\mathrm{P} 4$ year. This finding suggests that PharmD curricula, from the student's perspective, are adequately preparing them to perform expected entry-level responsibilities and tasks. Perhaps somewhat expectedly, $57 \%$ of students felt that overseeing the pharmacy operations for an assigned work shift was among the responsibilities they were least prepared to perform. This is an important pharmacy practice activity that is difficult to authentically simulate in pharmacy curricula or otherwise provide students with experience. As Zgarrick argues, this unit of pharmacy practice 


\section{American Journal of Pharmaceutical Education 2019; 83 (9) Article 7274.}

Table 4. Percent of Students Who Selected the EPA as a Top 3 Most or Least Prepared at This Point in Their Education

\begin{tabular}{|c|c|c|c|c|c|c|c|c|c|c|}
\hline \multirow[b]{2}{*}{ EPA Statement } & \multicolumn{5}{|c|}{$\begin{array}{c}\text { Percent of Students Selecting } \\
\text { Statement in Top } 3 \text { MOST } \\
\text { Prepared }\end{array}$} & \multicolumn{5}{|c|}{$\begin{array}{l}\text { Percent of Students Selecting } \\
\text { Statement in Top } 3 \text { LEAST } \\
\text { Prepared }\end{array}$} \\
\hline & $\begin{array}{c}\text { P1 } \\
\text { n=94 }\end{array}$ & $\begin{array}{c}\mathrm{P} 2 \\
\mathrm{n}=84\end{array}$ & $\begin{array}{c}\text { P3 } \\
\mathbf{n}=92\end{array}$ & $\begin{array}{c}\mathrm{P} 4 \\
\mathrm{n}=103\end{array}$ & $\begin{array}{r}\text { Total } \\
\mathbf{n}=373\end{array}$ & $\begin{array}{c}\mathrm{P} 1 \\
\mathrm{n}=94\end{array}$ & $\begin{array}{c}\mathrm{P2} \\
\mathrm{n}=84\end{array}$ & $\begin{array}{c}\mathrm{P3} \\
\mathrm{n}=92\end{array}$ & $\begin{array}{c}P 4 \\
n=103\end{array}$ & $\begin{array}{r}\text { Total } \\
\mathbf{n}=\mathbf{3 7 3}\end{array}$ \\
\hline \multicolumn{11}{|l|}{$\overline{\text { Patient Provider Role }}$} \\
\hline $\begin{array}{l}\text { Collect information to identify a patient's medication- } \\
\text { related problems and health-related needs. }\end{array}$ & $64^{\mathrm{a}}$ & $62^{\mathrm{a}}$ & $52^{\mathrm{a}}$ & $51^{\mathrm{a}}$ & $57^{\mathrm{a}}$ & 3 & 2 & 2 & 6 & 3 \\
\hline $\begin{array}{l}\text { Analyze information to determine the effects of } \\
\text { medication therapy, identify medication-related } \\
\text { problems, and prioritize health-related needs. }\end{array}$ & 14 & 16 & $33^{\mathrm{a}}$ & 26 & $22^{\mathrm{b}}$ & $32^{\mathrm{a}}$ & 23 & 12 & 16 & $20^{\mathrm{b}}$ \\
\hline $\begin{array}{l}\text { Establish patient-centered goals and create a care plan } \\
\text { for a patient in collaboration with the patient, } \\
\text { caregiver(s), and other health professionals that is } \\
\text { evidence-based and cost-effective. }\end{array}$ & 9 & 12 & 19 & 15 & 13 & $45^{\mathrm{a}}$ & $33^{\mathrm{a}}$ & $28^{\mathrm{a}}$ & $24^{\mathrm{a}}$ & $32^{\mathrm{b}}$ \\
\hline $\begin{array}{l}\text { Implement a care plan in collaboration with the } \\
\text { patient, caregivers, and other health professionals. }\end{array}$ & 8 & 4 & 5 & 12 & 7 & $32^{\mathrm{a}}$ & $33^{\mathrm{a}}$ & 27 & 21 & 28 \\
\hline Follow-up and monitor a care plan. & 18 & 17 & 12 & 14 & 15 & 10 & 10 & 14 & 14 & 12 \\
\hline \multicolumn{11}{|l|}{ Interprofessional Team Member Role } \\
\hline Collaborate as a member of an interprofessional team. & 26 & $37^{\mathrm{a}}$ & 26 & 27 & 29 & 11 & 12 & 13 & 9 & 11 \\
\hline \multicolumn{11}{|l|}{ Population Health Promoter Role } \\
\hline $\begin{array}{l}\text { Identify patients at risk for prevalent diseases in a } \\
\text { population. }\end{array}$ & 9 & 8 & 9 & 4 & 7 & 20 & 25 & 22 & 21 & 22 \\
\hline Minimize adverse drug events and medication errors. & 9 & 16 & 24 & 15 & $16^{\mathrm{b}}$ & 23 & 15 & 12 & 13 & 16 \\
\hline $\begin{array}{l}\text { Maximize the appropriate use of medications in a } \\
\text { population. }\end{array}$ & 4 & 7 & 8 & 7 & 6 & 17 & 20 & 22 & 21 & 20 \\
\hline $\begin{array}{l}\text { Ensure that patients have been immunized against } \\
\text { vaccine-preventable diseases. }\end{array}$ & $40^{\mathrm{a}}$ & 26 & 28 & 21 & $29^{\mathrm{ab}}$ & 4 & 6 & 8 & 5 & 6 \\
\hline \multicolumn{11}{|l|}{ Information Master Role } \\
\hline $\begin{array}{l}\text { Educate patients and professional colleagues regarding } \\
\text { the appropriate use of medications. }\end{array}$ & 14 & 27 & 19 & $29^{\mathrm{a}}$ & 22 & 28 & 11 & 9 & 5 & $13^{\mathrm{b}}$ \\
\hline $\begin{array}{l}\text { Use evidence-based information to advance patient } \\
\text { care. }\end{array}$ & 5 & 7 & 9 & 17 & 10 & 15 & 25 & 18 & 20 & 20 \\
\hline \multicolumn{11}{|l|}{ Practice Manager Role } \\
\hline $\begin{array}{l}\text { Oversee the pharmacy operations for an assigned work } \\
\text { shift. }\end{array}$ & 9 & 5 & 10 & 17 & 10 & 31 & $45^{\mathrm{a}}$ & $52^{\mathrm{a}}$ & 57 & $47^{\mathrm{ab}}$ \\
\hline Fulfill a medication order. & $68^{\mathrm{a}}$ & $54^{\mathrm{a}}$ & $46^{\mathrm{a}}$ & $45^{\mathrm{a}}$ & $53^{\mathrm{a}}$ & 5 & 2 & 10 & 15 & $8^{\mathrm{b}}$ \\
\hline \multicolumn{11}{|l|}{ Self-Developer Role } \\
\hline $\begin{array}{l}\text { Create a written plan for continuous professional } \\
\text { development. }\end{array}$ & 5 & 4 & 2 & 3 & 4 & 24 & $37^{\mathrm{a}}$ & $51^{\mathrm{a}}$ & $53^{\mathrm{a}}$ & $42^{\mathrm{ab}}$ \\
\hline
\end{tabular}

requires the same purposeful curricular design as pharmacotherapy to prepare students for direct patient care roles. ${ }^{11}$ Our results suggest students do not feel ready to carry out this practice management role. The percentage of students who identified this EPA among the roles they were least prepared to perform steadily increased with each year of the curriculum, suggesting students may become more aware of the complexity of managing pharmacy operations as they progress through the program.
Similarly, "Create a written plan for continuous professional development" was increasingly identified as a responsibility pharmacy students were least prepared to do as they progressed through the curriculum. This may have been because of students' growing awareness of the importance and difficulty in maintaining their knowledge and skills in a rapidly evolving field. However, this EPA statement was also ranked lower on both relevancy and expectation in multiple settings, so feeling less prepared to 


\section{American Journal of Pharmaceutical Education 2019; 83 (9) Article 7274.}

perform this EPA may have simply reflected a perceived lack of importance. This differs from the EPA statement "Establish patient-centered goals and create a care plan,". While among the top three EPAs students felt the least confident about, the percentage steadily declined from P1 to $\mathrm{P} 4$, potentially suggesting that as students acquired additional knowledge and experience, their confidence to perform this activity increased. While students' belief in their ability to independently perform EPAs appears to increase over time, colleges and schools of pharmacy still need to develop assessments to document that students can independently perform the EPAs. ${ }^{1}$

In 2017, senior medical students were surveyed to measure their self-perceived readiness for residency based on the Association of American Medical Colleges 13 EPA statements. ${ }^{12}$ Similar to the findings from our study, alignment was found between student and other medical stakeholder perspectives. Rhodes and colleagues also found agreement between student learners at University of North Carolina Eshelman School of Pharmacy (UNC) and preceptors within early pharmacy practice education experiences using an institution-specific EPA list that predated the AACP EPA statements, but most mapped to the AACP EPA statements. ${ }^{7}$ While a direct comparison between projects is difficult because of different research questions, the P2 pharmacy student responses in Table 3 and the P2 pharmacy student self-ratings of entrustability in the UNC project show similar levels of student confidence at the midpoint of the UNC immersion experience, but much higher levels of confidence at the final evaluation point for UNC students. The UNC P2 pharmacy students rated their level of entrustability as a 4 (independent) on nine of the 14 UNC EPA statements by the end of the two-month immersion experience. ${ }^{7}$ The discrepancies could be related to the confidence that comes with being in the practice setting, an incomplete student understanding of the complexity associated with units of pharmacy practice, and differing descriptors for each level of supervision. The UNC P2 students, similar to the P2 students in this project, confirmed the relevancy of the EPA statements to pharmacy practice in multiple settings.

Obtaining pharmacy student input is valuable information needed to align expectations and to guide curricular priorities. This research adds to the accumulating evidence that the AACP list of EPAs for new pharmacy graduates are perceived as relevant to the practice of pharmacy and expected of pharmacists in multiple setting by multiple stakeholder groups.

The results of this study, while compelling, must be taken into context with potential limitations. Student participants were drawn from four colleges of pharmacy located in the Midwest and Southern regions of the United States. While most participants were within the common age range for pharmacy students, students at the four institutions varied in age, pharmacy work experience, and prior knowledge of EPAs, reflecting the differences in the regional program structures. While these four schools could be classified as geographically diverse (ie, not located in the same state), generalizability to other pharmacy schools may be limited. Pharmacy students at schools in states with different practice laws and regulations may hold different beliefs about the relevancy of the EPAs and the professional activities that pharmacists are expected to perform. Also, while we reached our target number of student participants in each program year at each institution, the overall response rate was less than $50 \%$. Whether participation bias was present is unknown, ie, there is no way to know whether nonresponders would have felt differently than the responders did about the EPA statements. However, our power analysis and multistep sampling process yielded the needed sample size by institution and by program year, determined a priori, to find statistical differences among the responses received. This study represents a snapshot of pharmacy student beliefs, which likely will change over time. However, surveying students in each year of the PharmD program provides general insights into beliefs among students as they progress through the PharmD program. Finally, the QUEPA tool was developed and validated to assess the quality of EPA statements for internal medicine residency programs. ${ }^{13}$ The QUEPA tool was modified for the purpose of this study and has not been validated in settings beyond internal medicine residency programs.

\section{CONCLUSION}

Pharmacy students at four universities consistently agreed that the core EPA statements were relevant to pharmacy practice and that pharmacists were expected to perform these activities in multiple settings. The students self-rated their ability to perform the EPAs in an increasingly independent manner as they progressed through the PharmD curricula. Students believed they were most prepared to collect information to identify patient medication-related problems and health-related needs and to fulfill medication orders. Conversely, they felt least prepared to oversee pharmacy operations for a work shift, create a written plan for continuous professional development, and establish patient-centered goals and care plans.

\section{ACKNOWLEDGMENTS}

The authors thank Sophia Gleason for her assistance in the preparation of this manuscript.

\section{REFERENCES}

1. Haines ST, Pittenger AL, Stolte SK, et al. Core entrustable professional activities for new pharmacy graduates. Am J Pharm Educ. 2017;81(1):S2. doi:10.5688/ajpe811S2. 


\section{American Journal of Pharmaceutical Education 2019; 83 (9) Article 7274.}

2. ten Cate O, Scheele F. Viewpoint: competency-based postgraduate training: can we bridge the gap between theory and clinical practice? Acad Med. 2007;82(6):542-547. doi: 10.1097/ ACM.0b013e31805559c7.

3. Association of American Medical Colleges (AAMC). Core Entrustable Professional Activities (EPAs) for Entering Residency. https://www.aamc.org/system/files/c/2/484778-epa13toolkit.pdf. Accessed June 21, 2018.

4. Haines ST, Pittenger AL, Gleason BL, et al. Validation of the entrustable professional activities for new pharmacy graduates. AJHP. 2018;75(23):1922-1929. doi: 10.2146/ajhp170815. https:// www.ncbi.nlm.nih.gov/pubmed/30104260

5. Haines ST, Gleason BL, Kantorovich A, et al. Report of the 20152016 Academic Affairs Standing Committee. Am J Pharm Educ. 2016;80(9):S20. doi:10.5688/ajpe809S20.

6. Pittenger AL, Chapman SA, Frail CK, Moon JY, Undeberg MR, Orzoff JH. Entrustable professional activities for specialty pharmacy practice. Am J Pharm Educ. 2016;80(10):Article 178.

7. Rhodes L, Weck Marciniak M, McLaughlin J, Melendez C, Leadon K, Pinelli N. Exploratory analysis of entrustable professional activities as a performance measure during early practice experiences in a doctor of pharmacy program. Am J Pharm Educ. 2017;83(2):Article 6517. doi:10.5688/AJPE6517.

8. Jarrett J, Berenbrok L, Goliak K, Meyer S, Shaughnessy A. Entrustable professional activities: a novel framework for pharmacy education. Am J Pharm Educ. 2018;82(5):6256.

9. Setia MS. Methodological series module 5: sampling strategies. Ind J Dermatol 2016;61:505-509.

10. Jessen RJ. Statistical Survey Techniques. Hoboken, NJ: John Wiley and Sons, 1978.

11. Zgarrick DP. "Assure" Foundation for Management and Leadership in Pharmacy Curricula. Pulses. Curr Pharm Teach Learn. Scholarly Blog. https://cptlpulses.com/2017/09/05/assurefoundation-for-management-and-leadership-in-pharmacy-curricula/. Published September 5, 2017. Accessed January 5, 2019.

12. Strowd RE, McBride A, Goforth J, et al. Educational priorities of students in the entrustable professional activity era. Clin Teach. 2017;14:1-6. doi: 10.1111/tct.12688.

13. Post JA, Wittich CM, Thomas KG, et al. Rating the quality of entrustable professional activities: content validation and associations with the clinical context. J Gen Intern Med. 2016. doi:10.1007/s11606-016-3611-3618. 